concentration, urges to nap, sleeping at school, in the car, and a sensation of dreaming while awake $(\mathrm{p}<0.05)$. Headache patients with insomnia had trouble falling asleep, awakening suddenly after sleep onset, and feeling anxious about sleeping $(\mathrm{p}<0.05)$. Those with sleep apnea slept with mouths open $(\mathrm{p}<0.05)$. Headache patients had a more frequent history of seizures, dental problems, muscle disease $(\mathrm{p}<0.05)$, more frequent morning headaches, causing awakening, and nighttime arousals ( $\mathrm{p}<0.005$ ). (Luc ME, Gupta A, Birnberg JM, et al. Characterization of symptoms of sleep disorders in children with headache. Pediatr Neurol January 2006;34:7-12). (Respond: Dr Michel H Kohrman, Mc3055, University of Chicago, Dept of Pediatrics, 5841 S Maryland, Chicago, IL 60637).

COMMENT. A case history of a child presenting with headache should inquire about daytime sleepiness, narcolepsy, and insomnia. Children with headaches have more frequent symptoms of primary sleep disorders, and treating the sleep disorder may benefit the headache and improve the quality of life. Both headache and sleep disorders can be triggered by changes in neurotransmitters, and a fall in serotonin levels will affect REM sleep (Dodick DW et al. Headache 2003;43:282-292).

\title{
TOPIRAMATE IN ALTERNATING HEMIPLEGIA OF CHILDHOOD
}

A 12-year-old girl with a family history of migraine and attacks of hemiplegia was treated successfully with topiramate (TPM), in a report from the University Hospital of Messina, Italy; and Leiden University Medical Centre, The Netherlands. Hemiplegic attacks began at 7 months of age, they averaged 2 or 3 times per week, lasted 24 to 36 hours, resolved with sleep, shifted from one side to the other, and were associated with pendular nystagmus. Attacks were triggered by emotional stimuli or fever. Her psychomotor development was delayed; she talked at 3 years and walked at age 4.5 years. A video-EEG showed posterior slow waves during an attack of hemiplegia. At follow-up she had dystonia, dysarthria, ataxia, and pyramidal tract signs. Treatment with valproate, carbamazepine, and benzodiazepine failed to control attacks, and flunarazine $5 \mathrm{mg} /$ day reduced duration of attacks to 2 to 3 hours for 5 months, Attacks and motor and social skills worsened, and her IQ measured by the WISC was 48 . TPM was introduced, $1-3 \mathrm{mg} / \mathrm{kg} /$ day, with a prompt reduction in severity and frequency of attacks, and continued improvement of dystonia and ataxia through 18-month follow-up. The mechanism of action was attributed to the inhibition of carbonic anhydrase. (Di Rosa G, Spano M, Pustorino G, et al. Alternating hemiplegia of childhood successfully treated with topiramate: 18 months of follow-up. Neurology January (1 of 2);66:146). (Reprints: Dr Gabriella Di Rosa, Medical and Surgical Pediatrics, Division of Infantile Neuropsychiatry, University Hospital of Messina, via Consolare Valeria 98125, Messina, Italy).

COMMENT. Alternating hemiplegia of childhood (AHC) typically begins in infancy, and the etiology is unknown. It resembles migraine and familial hemiplegic migraine (FHM), but only a few familial cases of $\mathrm{AHC}$ have been reported (Mikati MA et al. Neurology 1992;42:2251-2257; Andermann E et al. Neurology 1994;44:1812-1814; Sakuragawa N. Brain Dev 1992;14:283-288; Ped Neur Briefs Jan 1993 and Nov 1994). Flunarazine is the most frequently used treatment, with variable response. In the present case, TPM was effective and deserves further study. 